\title{
Rapamycin Protects Skin Fibroblasts from Ultraviolet B-Induced Photoaging by Suppressing the Production of Reactive Oxygen Species
}

\author{
Dengke Qin ${ }^{a, b}$ Runjian Ren ${ }^{b, c} \quad$ Chuanlong Jiaa,b Yongzhou Lu ${ }^{a, b} \quad$ Qingjian Yanga,b \\ Liang Chen ${ }^{a, b}$ Xinyuan Wu $u^{a, b}$ Jingjing Zhu ${ }^{a, b}$ Yu Guo ${ }^{a, b}$ Ping Yang ${ }^{a, b}$ \\ Yiqun Zhou ${ }^{\mathrm{a}, \mathrm{b}}$ Ningwen Zhu ${ }^{\mathrm{d}}$ Bo Bib,c Tianyi Liü ${ }^{\mathrm{a}, \mathrm{b}}$

\begin{abstract}
aDepartment of Plastic and Reconstructive Surgery, Hua Dong Hospital, Fu Dan University, Shanghai, bShanghai Key Laboratory of Clinical Geriatric Medicine, Hua Dong Hospital, Fu Dan University, Shanghai, 'Department of Laboratory Medicine, Hua Dong Hospital, Fu Dan University, Shanghai, dDepartment of Dermatology, Hua Shan Hospital, Fu Dan University, Shanghai, China
\end{abstract}

\section{Key Words}

Uvb • ROS • Rapamycin • Autophagy

\begin{abstract}
Background/Aims: Ultraviolet B (UVB) irradiation alters multiple molecular pathways in the skin, thereby inducing skin photoaging. Murine dermal fibroblasts (MDFs) were subjected to a series of 4 sub-cytotoxic UVB doses $\left(120 \mathrm{~mJ} / \mathrm{cm}^{2}\right)$, resulting in changes in cell shape, DNA damage, cell cycle arrest, extracellular matrix variations, reactive oxygen species (ROS) generation, and alterations in major intracellular antioxidant and cellular autophagy levels. Rapamycin (RAPA) is a new macrolide immunosuppressive agent that is primarily used in oncology, cardiology, and transplantation medicine and has been found to extend the lifespan of genetically heterogeneous mice. Several studies have shown that RAPA may have anti-aging effects in cells and organisms. Thus, in this study, we explored the effects and mechanisms of RAPA against the photoaging process using a well-established cellular photoaging model. Methods: We developed a stress-induced premature senescence (SIPS) model through repeated exposure of MDFs to ultraviolet B (UVB) irradiation. The cells were cultured in the absence or presence of RAPA for $48 \mathrm{~h}$. Senescent phenotypes were assessed by examining cell viability, cell morphology, senescence-associated $\beta$-galactosidase (SA- $\beta$-gal) expression, cell cycle progression, intracellular ROS production, matrix metalloproteinase (MMP) synthesis and degradation, extracellular matrix (ECM) component protein expression, alterations in major intracellular antioxidant levels, and the cellular autophagy level. Results: Compared with the UVB group, pretreatment with RAPA $(5 \mu \mathrm{M})$ significantly decreased the staining intensity and percentage of SA- $\beta$-gal-positive cells and preserved the elongated cell shape. Moreover, cells pretreated with RAPA showed inhibition of the reduction in the type I collagen content by blocking the UVB-induced upregulation of MMP expression. RAPA also decreased photoaging cell cycle arrest and downregulated p53 and p21 expression. RAPA application significantly

D. Qin and R. Ren contributed equally to this work.

Dr. Tianyi Liu 221 West Yan'an Rd, Hua Dong Hospital,

Fu Dan University, Shanghai (China)

Tel. 62483180, E-Mail tianyiliucn@126.com
\end{abstract}




\section{Cellular Physiology Cell Physiol Biochem 2018;46:1849-1860 \\ \begin{tabular}{c|c|c|c|} 
DOI: 10.1159/000489369 & O 2018 The Author(s). Published by S. Karger AG, Basel \\
wwww.karger.com/cpb
\end{tabular} \\ Qin et al.: Rapamycin Protects Skin Fibroblasts from UVB Irradiation}

attenuated irradiation-induced ROS release by modulating intracellular antioxidants and increasing the autophagy level. Conclusions: Our study demonstrated that RAPA elicited oxidative damage in vitro by reducing ROS accumulation in photoaged fibroblasts. The anti-aging effect can be attributed to the maintenance of normal antioxidant and cellular autophagy levels. However, determination of the definitive mechanism requires further study.

(C) 2018 The Author(s)

Published by S. Karger AG, Basel

\section{Introduction}

Skin aging is a complex, progressive process that involves intrinsic and extrinsic factors [1]. Extrinsic aging occurs due to environmental aggressors, including ultraviolet (UV) irradiation, smoke, and common pollutants [2], whereas exposure to ultraviolet (UV) radiation (particularly UVB) is the leading factor in extrinsic aging, which is also known as photoaging [3]. Dermal fibroblasts, which are the predominant cell type in the dermis, are responsible for regulating the extracellular matrices, interstitial fluid volume and pressure, collagen production, and wound healing [4]. These cells play important roles in antiphotoaging and maintenance of the normal structure and function of the skin. Repetitive exposure to UVB increases the cellular reactive oxygen species (ROS) level, resulting in strand breaks and hydroxylation of DNA bases [5]. UVB can induce cell cycle arrest and mutagenic DNA damage, such as formation of cyclobutane pyrimidine dimers (CPDs) and pyrimidine (6-4) pyrimidone photoproduct $[6,7]$. These changes have detrimental effects that include carcinogenesis, cell senescence, and other skin pathologies [8]. Enhanced ROS levels induce the production of matrix metalloproteinases (MMPs), which can degrade extracellular matrix components and inhibit collagen synthesis, causing skin relaxation, wrinkles, and erythema [9]. Additionally, excessive ROS levels can disrupt the balance of the oxidation/antioxidant system, resulting in the dysregulated secretion of antioxidants, such as superoxide dismutase (SOD), catalase (CAT), and glutathione peroxidase (GPx) [10-13]. Given the important role of ROS, reducing ROS accumulation is a future approach for skin photoprotection.

Rapamycin (RAPA) is an inhibitor of mammalian TOR (mTOR), which is a serine/ threonine kinase that promotes a broad physiological profile of growth, nutrient storage, and anabolic metabolism in response to high nutrient availability [14-16]. As a new drug with both immunosuppressant and antiproliferative properties, RAPA has been widely used to treat refractory acute rejection and neurodegenerative diseases, such as Parkinson and Alzheimer's diseases [17]. Halloran et al. reveled that RAPA treatment extended the median and maximal lifespans of both male and female mice when the treatment began at 600 days of age [18]. Chad et al. found that RAPA reduced the ROS levels within cells and increased the lifespans of normal human fibroblasts [19]. Timothy et al. demonstrated that RAPA prevented ROS production and scavenged the damaged mitochondrial DNA depletion induced by ethidium bromide [20]. The anti-aging effect of RAPA is generally thought to be primarily mediated through its ability to reduce ROS accumulation.

Autophagy is a dynamic process in which unnecessary or dysfunctional organelles and proteins are degraded [21]. RAPA can induce autophagy through inhibition of mTOR. Several studies have shown that a reduction in autophagy can accelerate the aging process, whereas stimulation of autophagy may have potent anti-aging effects [22]. Zhang et al. found that antagomir-mediated inactivation of miR-23a protected human fibroblasts from premature senescence resulting from a PUVA- and UVB-mediated decrease in the autophagy flux [23]. Satoko et al. reported that inadequate autophagy accelerated bronchial epithelial cell senescence in chronic obstructive pulmonary disease [24]. Motoko et al. suggested that autophagy might mediate the biliary epithelial cell senescence process induced by primary biliary cirrhosis [25]. However, the potential effects and mechanisms of RAPA on UVB irradiation-induced photoaged fibroblasts remain unknown.

The effects of UVB on autophagy levels are ambiguous. Zhang et al. found that $25 \mathrm{~mJ} /$ $\mathrm{cm}^{2}$ of UVB irradiation performed twice daily for 5 days repressed autophagy [23]. Liu 


\section{Cellular Physiology Cell Physiol Biochem 2018;46:1849-1860

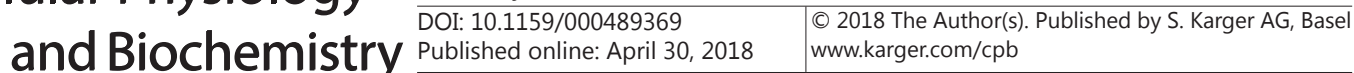 \\ Qin et al.: Rapamycin Protects Skin Fibroblasts from UVB Irradiation}

et al. illustrated that UVB repressed the autophagic flux in A431 cells via the autophagyrepressive signaling pathway [26]. However, Yang et al. found that UVB induced autophagy in JB6 epidermal cells through the GSK3b/AMPK pathway, and Chen et al. illustrated that UV induced an on-rate autophagic flux in A549 and H1299 cells [27, 28]. Based on these findings, we speculated that the influence of UVB-irradiation on the cellular autophagic flux depended on the characteristic features of the cell types and the UVB-SIPS model.

The purpose of this study is to test the role of RAPA in the photoaging process at a cellular level and to examine its potential mechanisms. Previously, we established a reproducible photodamage model of murine dermal fibroblasts (MDFs) through repeated UVB exposure, which demonstrated a series of senescence-like phenotypes, including a flattened morphology, positive SA- $\beta$-gal staining, long-term growth arrest, increased MMP synthesis and extracellular matrix (ECM) degradation, ROS generation, and alterations in the major intracellular antioxidant and cellular autophagy levels. The present study was conducted to evaluate the potential of RAPA against repeated UVB irradiation-induced photoaging in MDFs.

\section{Materials and Methods}

\section{Cell culture conditions and UVB irradiation procedure}

MDFs were isolated from the dorsal dermis of newborn littermate C57BL/6 mice 18-24 h after birth as previously described [29]. The cells were grown as a monolayer and maintained in DMEM containing $10 \%$ fetal bovine serum (FBS), $1 \%$ glutamine, $100 \mathrm{U} / \mathrm{mL}$ of penicillin, and $100 \mu \mathrm{g} / \mathrm{mL}$ of streptomycin at $37{ }^{\circ} \mathrm{C}$ in a $5 \% \mathrm{CO}_{2}$ atmosphere. The fibroblasts grew normally from the explants after 4-5 days and were harvested at $80 \%$ confluence. Cells at passages 1-3 were used in this study. At $12 \mathrm{~h}$ after plating, the cells were treated with RAPA in DMEM containing 10\% FBS for $48 \mathrm{~h}$; then, the medium was removed, and the cells were washed three times with phosphate-buffered saline (PBS). The cells were covered with a thin layer of PBS and exposed to a 4-dose series of UVB irradiation at $120 \mathrm{~mJ} / \mathrm{cm}^{2}$ (Narrowband TL $20 \mathrm{~W} / 01 \mathrm{RS}$ lamp, Philips, the Netherlands) for $120 \mathrm{~s}$ with an interval time of $12 \mathrm{~h}$ as previously described [30]. In this study, we present a model of stress-induced premature senescence (SIPS) through repeated exposure of MDFs at early passages (passages 1-3) to a series of 4 sub-cytotoxic doses of UVB $\left(120 \mathrm{~mJ} / \mathrm{cm}^{2}\right)$. Although the CCK-8 results showed that the cell viability was decreased by $30 \%$ after the series of 4 sub-cytotoxic doses of UVB (120 mJ/ $\left.\mathrm{cm}^{2}\right)$, the reduced viability did not affect our subsequent experiments [30]. After 4 UVB exposures, the cells were incubated for $24 \mathrm{~h}$ in DMEM with $10 \%$ FBS and then subjected to various biochemical investigations.

\section{Cell assays and choice of the rapamycin concentration}

A CCK-8 kit was purchased from Beyotime Institute Biotech, China. The viability of MDFs exposed to RAPA $(0-10 \mu \mathrm{M})$ for up to $72 \mathrm{~h}$ was determined using the kit according to the manufacturer's instructions. Briefly, cells were seeded into a 96 -well plate with a 4.5 - mm well diameter $\left(5 \times 10^{3}\right.$ cells/well). After $12 \mathrm{~h}$, the medium was replaced with DMEM containing increasing doses of RAPA, and the cells were cultured at $37{ }^{\circ} \mathrm{C}$ in a $5 \% \mathrm{CO}_{2}$ atmosphere for another $72 \mathrm{~h}$. After treatment, the medium was removed, and the cells were washed two times with PBS and incubated in the dark with $10 \mu \mathrm{L}$ of CCK-8 solution for 2 h. Finally, the absorbance was measured at $450 \mathrm{~nm}$ using a Varioskan Flash Spectral Scanning Multimode Reader (Thermo Electron Corporation, USA). Alterations in the viability of the RAPA-treated fibroblasts compared to untreated cells are expressed as OD values.

\section{SA- $\beta$-gal staining}

To examine a biomarker of senescence, senescence-associated SA- $\beta$-gal staining was performed as previously described. We purchased the staining kit from Cell Signaling Technology (\#9860, Boston, MA, USA). After washing with PBS ( $\mathrm{pH} \mathrm{6.0),} \mathrm{the} \mathrm{cells} \mathrm{were} \mathrm{fixed} \mathrm{in} \mathrm{4 \%} \mathrm{paraformaldehyde} \mathrm{for} 10 \mathrm{~min}$ (room temperature) and stained according to the manufacturer's protocol. The number of SA- $\beta$-gal-positive cells was determined by counting 400 cells per dish using the Image Pro Plus (IPP) 6.0 software (Media Cybernetics, Bethesda, MD, USA). The proportions of cells positive for SA- $\beta$-gal activity are presented as the percentages of the total numbers of cells counted in each dish.

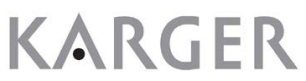




\section{Cellular Physiology Cell Physiol Biochem 2018;46:1849-1860 \begin{tabular}{l|l|l} 
and Biochemistry $10.1159 / 000489369$ & $\begin{array}{l}\text { DO } 2018 \text { The Author(s). Published by S. Karger AG, Basel } \\
\text { www.karger.com/cpb }\end{array}$
\end{tabular} \\ Qin et al.: Rapamycin Protects Skin Fibroblasts from UVB Irradiation}

Fluorescence microscopy to evaluate the cell morphology

The cells were fixed with $4 \%$ paraformaldehyde and permeabilized with $0.3 \%$ Triton X-100 at room temperature for $15 \mathrm{~min}$. After washing with PBS, the cells were incubated with freshly prepared FITC-phalloidin staining solution (Sigma Chemical Co., USA) for $30 \mathrm{~min}$. The nuclei were labeled with 4,6-diamidino-2-phenylindole (DAPI). Images were captured at 200× magnification using a fluorescence microscope (Olympus IX70-S1F2, Japan).

Flow cytometry analysis of the cell cycle and determination of cyclobutane pyrimidine dimer (CPD) photoproducts

Cells were harvested and trypsinized into single-cell suspensions and then fixed with $70 \%$ ethanol at $4{ }^{\circ} \mathrm{C}$ overnight. RNA was degraded by incubation with $1 \mathrm{mg} / \mathrm{mL}$ of RNase (Sigma-Aldrich, St. Louis, MO, USA) at $37^{\circ} \mathrm{C}$ for $1 \mathrm{~h}$. The DNA was labeled with $50 \mathrm{mg} / \mathrm{mL}$ of propidium iodide (PI; Sigma-Aldrich), and the DNA content was analyzed using a flow cytometer (Beckman Coulter, High Wycombe, UK) equipped with the ModiFit LT v2.0 software.

The cultured MDFs were treated with UVB irradiation at $120 \mathrm{~mJ} / \mathrm{cm}^{2}$ for $120 \mathrm{~s}$. immediately after irradiation, the PBS was aspirated and replaced with DMEM containing 1\% FBS. At different time points, the cells were washed in PBS, fixed in 75\% methanol/25\% acetic acid for $30 \mathrm{~min}$, and denaturated for $15 \mathrm{~min}$ at room temperature. The wells were aspirated and incubated with an anti-CPD antibody for $60 \mathrm{~min}$. Then, the cells were washed and incubated with the secondary FITC-conjugated antibody for 60 min (OxiSelect ${ }^{\mathrm{TM}}$ Cellular UV-Induced DNA Damage Staining Kit (CPD), Trial Size; Cell Biolabs, Inc., San Diego, CA, USA). The absorbance was determined at $450 \mathrm{~nm}$ using the Varioskan Flash Spectral Scanning Multimode Reader (Thermo Electron Corporation, USA).

\section{Adenoviruses for GFP-RFP-LC3}

At $24 \mathrm{~h}$ after the last UVB irradiation, the cells were seeded into $35-\mathrm{mm}$ dishes and cultivated for another $24 \mathrm{~h}$ before transfection. The cells were transfected with GFP-RFP- LC3 (purchased from Hanbio Co. Ltd., Shanghai, China) at a multiplicity of infection (MOI) of 100 for $24 \mathrm{~h}$. Briefly, the GFP-LC3 puncta in a single cell were manually counted under a microscope. For each group, 50 cells were randomly selected to obtain the average number of GFP-LC3 puncta/cell. The data presented were from one representative experiment of at least three independent repeats.

\section{RNA preparation and real-time RT-PCR}

At $24 \mathrm{~h}$ after the last UVB treatment, total RNA was extracted from the cells using the TRIzol reagent (Invitrogen, Carlsbad, CA, USA) and preserved at $-80^{\circ} \mathrm{C}$ prior to use. Then, $1 \mu \mathrm{g}$ of RNA was reverse-transcribed into cDNA using the AMV reverse transcriptase (Promega, Madison, WI, USA) in a 20- $\mu \mathrm{L}$ reaction solution that included $4 \mu \mathrm{L}$ of $5 \times$ buffer, $1 \mu \mathrm{L}$ of oligo-(dT), $1 \mu \mathrm{L}$ of dNTPs, $0.5 \mu \mathrm{L}$ of RNase inhibitor, and $0.5 \mu \mathrm{L}$ of AMV reverse transcriptase with double-distilled water to make up the final volume. The cDNA was amplified using a RT-PCR kit (Takara, Shiga, Japan); the primer sequences are listed in Table 1. The amplification reaction assays contained $1 \times$ SYBR Green PCR Mastermix and primers (Applied Biosystems, the Netherlands) at optimal concentrations. The following cycling parameters were used in the StrataGene Mx3000p System (Agilent Technologies, USA): $95^{\circ} \mathrm{C}$ for $10 \mathrm{~min}$, followed by 40 cycles of $95^{\circ} \mathrm{C}$ for $30 \mathrm{~s}, 60^{\circ} \mathrm{C}$ for $30 \mathrm{~s}$, and 72 ${ }^{\circ} \mathrm{C}$ for $45 \mathrm{~s}$. Melting curves were generated after amplification, and the data were analyzed using the Mxp software. Each sample was tested in triplicate, and three independent experiments were performed.

\section{Protein quantification and western blotting analysis}

The cells in each group were counted and lysed for protein quantification using a BCA kit (Pierce, USA). The amount of soluble protein was divided by the cell number as a marker of cellular hypertrophy (protein/cell). Western blotting analysis of cellular proteins was performed according to a previously described method [31]. For the analysis, total cellular proteins were isolated using RIPA

Table 1. RT-PCR primers

\begin{tabular}{ccc}
\hline Collagen I & F & CCA GTG GCG GTT ATG ACT \\
\hline & R & GCT GCG GAT GTT CTC AAT \\
MMP-1 & F & ACT TTG AGA ACA CGG GGA \\
& R & CGG GGA TAA TCT TTG TCC \\
MMP-2 & F & ATT CTG TCC CGA GAC CGC \\
& R & CAC CAC ACC TTG CCA TCG \\
MMP-3 & F & CAA GGG ATG ATG ATG CTG GTA TGG \\
& R & TGG GAT TTC CTC CAT TTT GG \\
MMP-9 & F & ACG ATA AGG ACG GCA AAT \\
& R & CA AAG ATG AAC GGG AAC AC \\
GAPDH & F & TGG TGA AGG TCG GTG TG \\
& R & GG TCA ATG AAG GGG TCG TT \\
\hline
\end{tabular}




\section{Cellular Physiology Cell Physiol Biochem 2018;46:1849-1860 \begin{tabular}{l|l} 
DOI: 10.1159/000489369 & Ond Biochemistry 2018 The Author(s). Published by S. Karger AG, Basel \\
wwww.karger.com/cpb
\end{tabular} \\ Qin et al.: Rapamycin Protects Skin Fibroblasts from UVB Irradiation}

buffer (Sigma-Aldrich, St. Louis, MO, USA) $48 \mathrm{~h}$ after RAPA treatment. For the cell cycle regulatory protein analysis, the cells were lysed $72 \mathrm{~h}$ after the final UVB irradiation. Equal amounts of protein from each group were separated on $12 \%$ SDS-PAGE gels for $60 \mathrm{~min}$ and blotted onto polyvinyl difluoride membranes. The blots were incubated with anti-p53, anti-p21, anti-collagen I, anti-SOD1, anti-SOD2, anti-CAT, and anti-GPX antibodies (all from Abcam, Cambridge, UK) and then washed and incubated with a horseradish peroxidaseconjugated secondary antibody. The bands were visualized via chemiluminescence (Pierce, Rockford, USA).

\section{Evaluation of the intracellular ROS levels}

Intracellular ROS were measured using the non-fluorescent probe 2, 7-dichlorodihydro-fluoresce in diacetate (DCFH-DA; Sigma-Aldrich Co., LLC, USA). Briefly, the cells were cultured in a six-well flat-bottomed plate, pretreated with DMEM containing RAPA for $48 \mathrm{~h}$, washed with PBS three times, and incubated with $5 \mathrm{mg} / \mathrm{mL}$ of DCFH2-DA at $37{ }^{\circ} \mathrm{C}$ for $20 \mathrm{~min}$ in the dark. Then, the cells were irradiated with UVB and subsequently analyzed with a fluorescence microscope and a Beckman Coulter Epics Altra flow cytometer (Beckman Coulter, High Wycombe, UK) equipped with the ModiFit LT v2.0 software as previously described. Fluorescence measurements were made at excitation and emission wavelengths of 494 and $518 \mathrm{~nm}$, respectively.

\section{Statistical analysis}

The statistical analyses were performed using the SPSS 13.0 (SPSS Inc., Chicago, IL, USA) software package. The paired Student's t-test was used for direct comparisons between the UVB and UVB + RAPA groups. For multiple comparisons, one-way ANOVA was applied. All values are expressed as the mean \pm S.D., and $\mathrm{p}<0.05$ was considered significant.

\section{Results}

\section{CCK-8 evaluation of proliferative activity}

To confirm the optimal RAPA concentration for the subsequent study, we assessed its cytotoxic effect at increasing concentrations ranging from 0 to $10 \mu \mathrm{M}$. The proliferative activity of MDFs (as assessed by the CCK-8 assay) showed no modification at any dose tested except $10 \mu \mathrm{M}$ (Fig. 1).

\section{RAPA decreased SA- $\beta$-gal staining}

The results demonstrated strong SA$\beta$-gal activity in the UVB-treated MDFs and a reduced staining intensity in the RAPA treatment group (Fig. 2A). In addition, the proportion of positively stained cells was significantly decreased in the RAPA treatment group (Fig. 2B).

Considering the positive SA- $\beta$-gal staining results, we used phalloidin to evaluate the cell morphology. The results revealed a flattened and enlarged senescentlike morphology in the UVB-treated cells. Compared with the UVB irradiation group, the cells pretreated with RAPA exhibited a morphology with a decreased length and width (Fig. 2C). The soluble protein content per cell in each group was determined to quantify the extent of cellular hypertrophy. Compared to the control group, a 4.3-fold increase in protein per cell was observed in

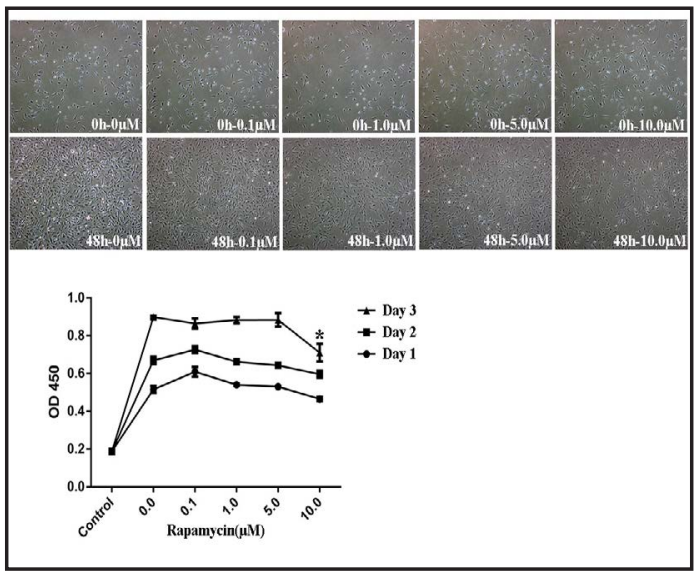

Fig. 1. Effects of RAPA on proliferation and morphology of MDFs. (A) MDFs were incubated for 24,48 , and 72 h with different RAPA concentrations (0-10 $\mu \mathrm{M})$, and images were captured showing the cell density. (B) The CCK-8 assay was used to analyze the proliferative activity of MDFs incubated with RAPA $(0-10 \mu \mathrm{M})$ for 24,48 , and $72 \mathrm{~h}$. The results are expressed as the OD value \pm SD. ${ }^{*} p<0.05$ compared to the Ctrl group. 
Fig. 2. Senescence-associated $\beta$-galactosidase (SA$\beta$-gal) staining of MDFs. (A) Relatively more SA$\beta$-gal+ cells were observed in the UVB irradiation group. The proportion of SA- $\beta$-gal+ cells was significantly lower in the UVB + RAPA group than in the UVB group. Fewer SA- $\beta$-gal+ cells were detected in the Ctrl and Ctrl + RAPA groups. (B) The ratio of cells positive for SA- $\beta$-gal activity was calculated by examining 400 cells per dish. The results are presented as the mean \pm SD of three independent experiments $\left({ }^{*} \mathrm{p}<0.05\right)$. (C) At $24 \mathrm{~h}$ after the last irradiation, we fixed the cells with $4 \%$ paraformaldehyde and stained F-actin with FITC-phalloidin. Original magnification $\times 200$. (D) After $24 \mathrm{~h}$, the cells were trypsinized and counted. The cells were lysed for immunoblotting, and

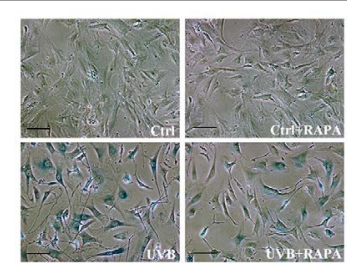

A

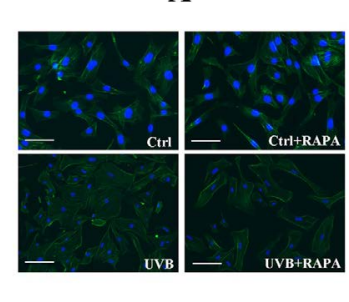

C
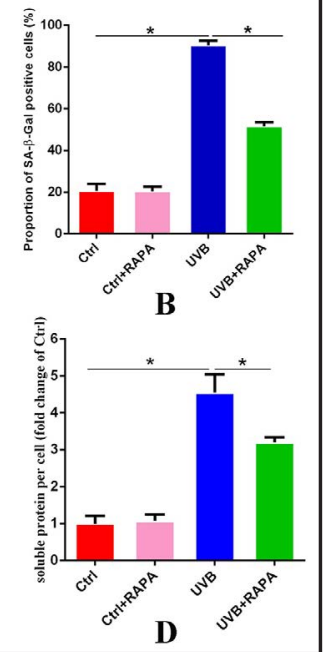
the soluble protein content in each group was measured. The soluble protein amount was divided by the cell number as a marker of cellular hypertrophy (protein/cell). The results are shown as the fold increase compared with the control group. The results represent the mean \pm SD of triplicate determinations $\left({ }^{*} \mathrm{p}<0.05\right)$.

Fig. 3. RAPA counteracted UVBinduced cell cycle arrest in MDFs. (A) At $48 \mathrm{~h}$ after the last irradiation, the cells were labeled with propidium iodide, and the cell cycle was analyzed using flow cytometry. (B) Western blotting for determination of the p53 and p21 expression levels at $24 \mathrm{~h}$ after the last UVB irradiation. Quantitative analysis of the p53 and p21 levels was performed using $\beta$-tubulin as a reference. (C) cyclobutane pyrimidine dimers (CPDs) formation in MDFs at different time points after treatment with UVB (120 mJ/cm2) irradiation alone. Each bar represents the mean \pm SD of three samples $\left({ }^{*} p<0.05\right)$.

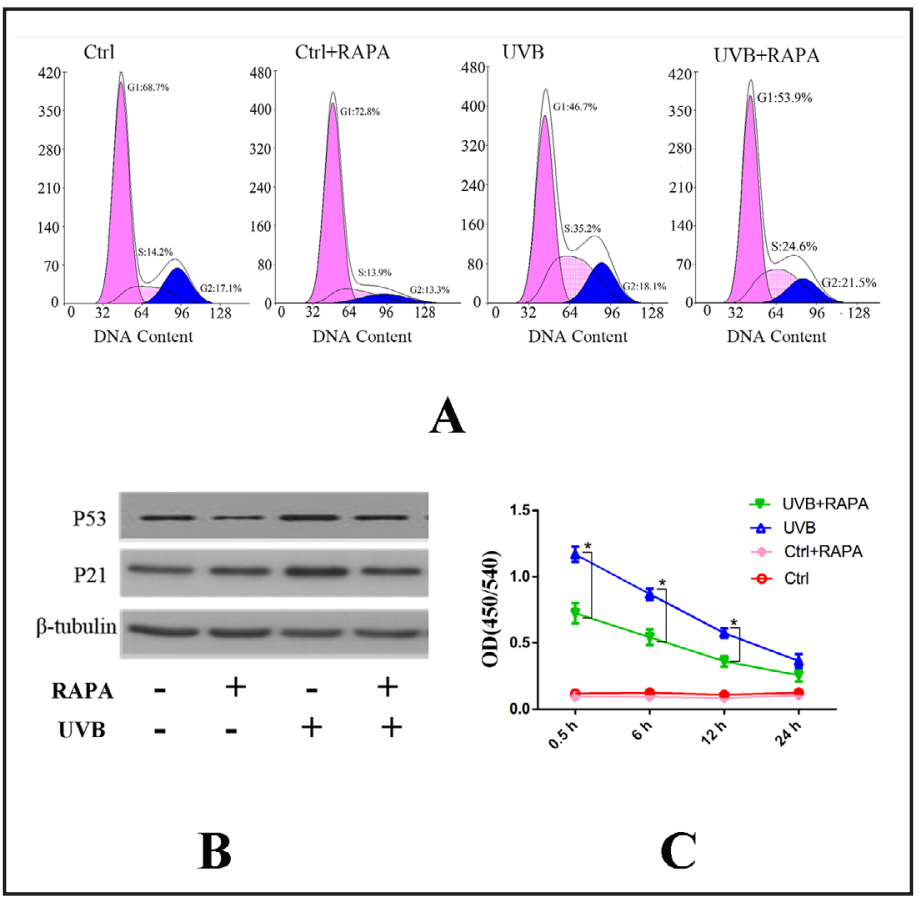

the UVB group; however, the soluble protein level per cell showed a significant decline after pretreatment with RAPA (Fig. 2D).

\section{RAPA counteracted UVB-induced cell cycle arrest and CPD formation}

UVB irradiation can decrease proliferative activity as a consequence of cell cycle arrest. Consistent with our previous report, UVB irradiation decreased the cell populations in the G0/G1 phase (from $68.7 \pm 2.12$ to $46.7 \pm 1.98 \%$ ). We found that RAPA prevented the S-phase cell cycle alteration to some extent compared with the UVB group (from $14.2 \pm 2.34 \%$ to 35.2 $\pm 1.87 \%$ ) (Fig. 3A). 
Fig. 4. RAPA stimulated autophagy in UVB-SIPS MDFs. (A) Western blotting analysis showing that pretreatment with RAPA induced autophagy, as evidenced by Beclin-1 and LC3-II expression. (B) Quantitative analysis of Beclin-1 and LC3-II expression was conducted using $\beta$-tubulin as a reference and expressed as the percentage of the protein level in the control cells. (C) Representative images showing LC3 staining in different groups of fibroblasts infected with the GFP-RFP-LC3 adenovirus for $24 \mathrm{~h}$. The yellow puncta indicate autophagosomes, and the red puncta indicate autolysosomes. Each bar represents the mean \pm SD of three samples $\left({ }^{*} p<0.05\right)$, and a representative image from three independent western blotting experiments is shown.

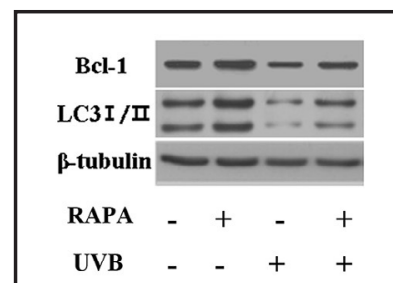

A

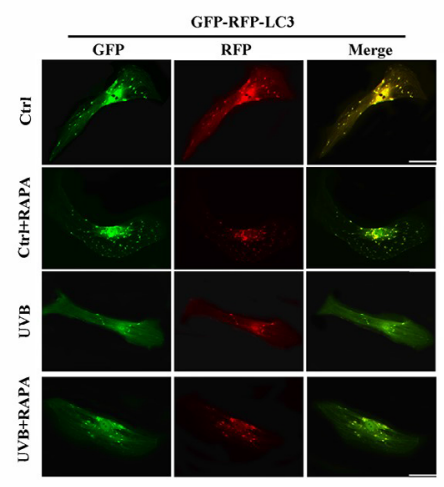

C

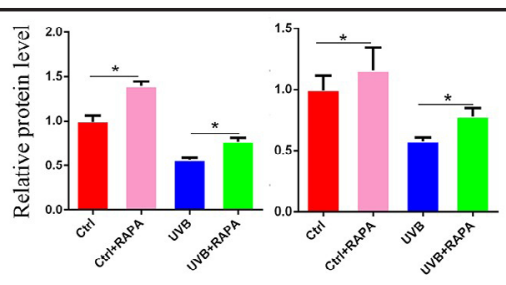

Bcl-1

LC3 II
B

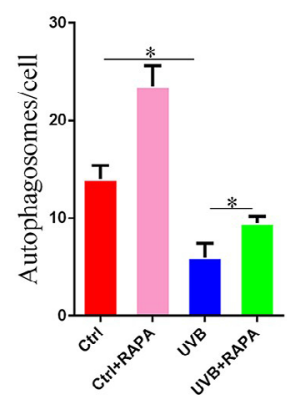

D

Fig. 5. Effect of RAPA on UVB irradiationinduced alterations in MMPs and type I collagen levels in MDFs. Real-time RT-PCR analysis of four MMP genes (MMP-1, -2, -3, and -9)

(A) and type I collagen

(B). The results are presented as the mean \pm SD of triplicate determinations $\quad\left({ }^{*} \mathrm{p}<0.05\right)$. (C) Type I collagen expression was detected by western blotting analysis $24 \mathrm{~h}$ after the last UVB irradiation. The results are presented as the mean \pm SD of triplicate determinations $\left({ }^{*} \mathrm{p}<0.05\right)$.

Next, we sought

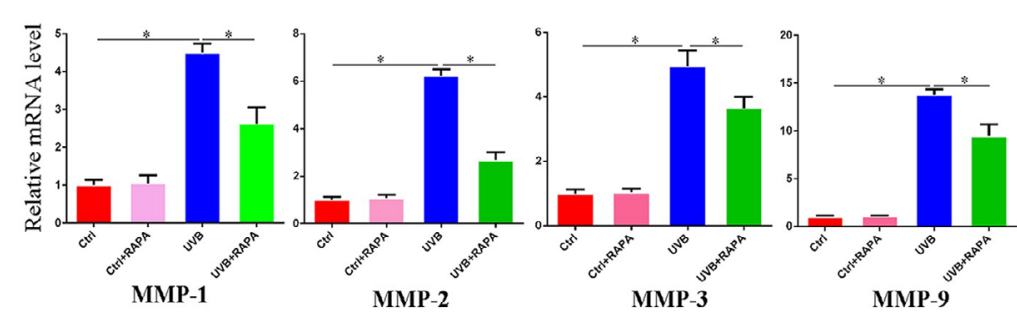

A

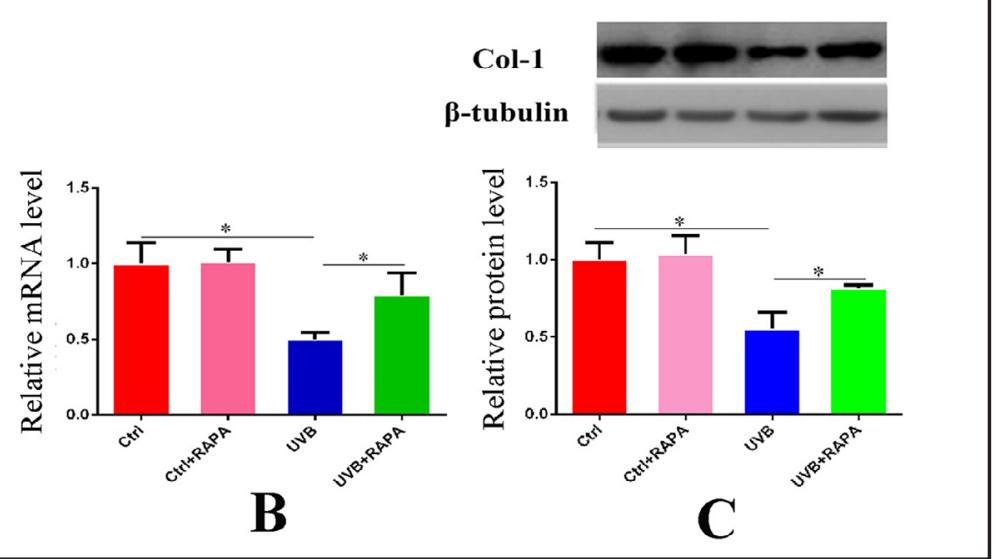

to determine the levels of p53 and p21, which are critical cell cycle regulators, and found that these levels were upregulated in senescent cells $24 \mathrm{~h}$ after the last irradiation. The western blotting analysis showed that p53 and p21 expression was significantly enhanced in the UVBtreated MDFs. Notably, the p53 and p21 levels increased by 2.0-and 1.7-fold, respectively, in the UVB group compared to the control group. Treatment with RAPA before UVB irradiation significantly downregulated p53 (1.3-fold) and p21 (1.4-fold) protein expression (Fig. 3B). 
Fig. 6. RAPA pretreatment decreases UVB-induced ROS accumulation and promotes antioxidant defense in MDFs. (A) MDFs were incubated in the absence or presence of RAPA for $48 \mathrm{~h}$ and then exposed to UVB irradiation or PBS treatment after a 20-min incubation with 5 mg mL-1 of DCFH2-DA. Original magnification $\times 40$. (B) Flow cytometry analysis of the mean fluorescence intensity in the UVB and UVB + RAPA groups after a 30-min incubation with $5 \mathrm{mg}$ mL-1 of DCFH2-DA. The mean fluorescence intensity of the two groups is shown in different colors. (C) The expression of the antioxidants SOD1, SOD2, and CAT, GPx was measured by western blotting analysis after $24 \mathrm{~h}$ of treatment in the absence or presence of RAPA. The protein
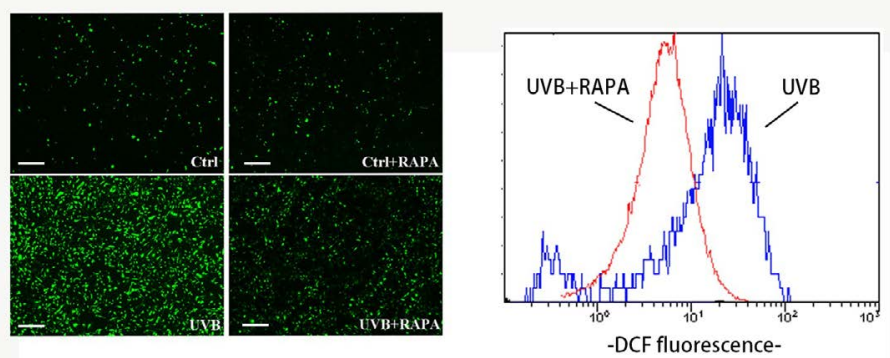

A

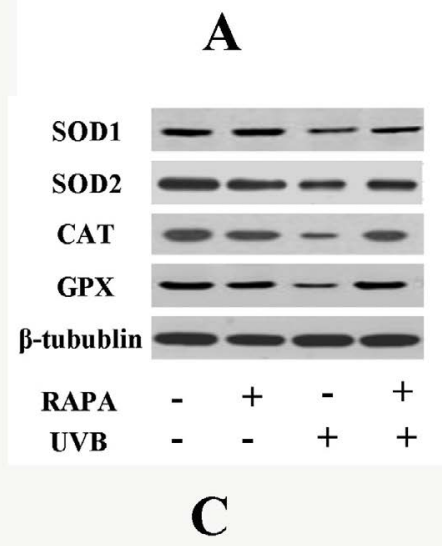

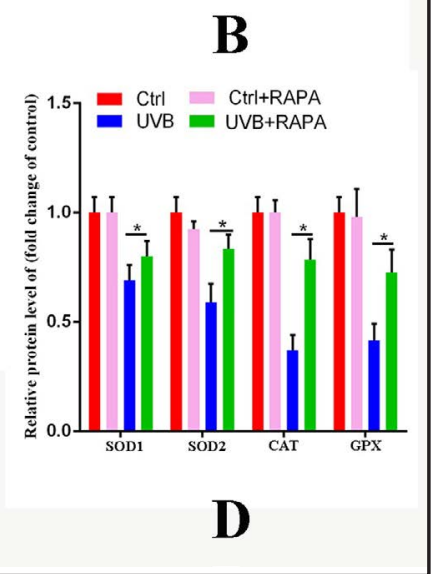

levels were quantified using $\beta$-tubulin as a reference and expressed as a fold change in the protein level compared with the control cells. The results are presented as the mean \pm SD of triplicate determinations $\left({ }^{*} \mathrm{p}<0.05\right)$.

The formation of cyclopyrimidine dimers (CPDs) is the hallmark of UVB-induced cell damage and is closely associated with the development of UVB-induced skin tumors. As demonstrated in Fig. 3C, UVB irradiation significantly increased the CPD level in the cultured MDFs. Conversely, RAPA treatment prior to UVB irradiation prevented CPD formation at every time point analyzed $(0.5 \mathrm{~h}, 6 \mathrm{~h}, 12 \mathrm{~h})$.

\section{RAPA stimulated autophagy in UVB-SIPS MDFs}

After UVB irradiation, both autophagosomes (yellow puncta) and autolysosomes (red puncta) were decreased in the photoaged cells, and this decrease was ameliorated by pretreatment with RAPA (Fig. 4C and D). The western blotting analysis showed that UVB irradiation reduced the expression of autophagy-related proteins, including Beclin-1 and LC3-II. These findings revealed that the autophagy level was reduced in our photodamaged model. However, pretreatment with RAPA increased Beclin-1 and LC3-II expression (Fig. 4A and B). Therefore, RAPA significantly reduced the suppression of autophagy induced by UVB irradiation.

\section{RAPA prevented MMP secretion and type I collagen degradation in UVB-induced MDFs}

UVB irradiation has been reported to decrease type I collagen expression and increase MMP expression, including MMP-1, $-2,-3,-7$, and -9 . At $24 \mathrm{~h}$ after the last irradiation, the expression of MMPs was significantly increased, including MMP-1, $-2,-3$, and -9 , and type I collagen expression was decreased at the mRNA and protein levels in the UVB group. Moreover, pretreatment with $5 \mu \mathrm{M}$ RAPA significantly counteracted the increase in MMP-1, $-2,-3$, and -9 expression at the mRNA and protein levels (Fig. 5A) and prevented the UVB irradiation-induced downregulation of type I collagen at the mRNA and protein levels in the UVB plus RAPA group (Fig. 5B and C). 


\section{Cellular Physiology Cell Physiol Biochem 2018;46:1849-1860 \begin{tabular}{ll|l} 
DOI: 10.1159/000489369 & O 2018 The Author(s). Published by S. Karger AG, Basel \\
www.karger.com/cpb
\end{tabular} \\ Qin et al.: Rapamycin Protects Skin Fibroblasts from UVB Irradiation}

RAPA pretreatment decreased UVB-induced ROS accumulation and promoted antioxidant defense in MDFs

According to our previous study, a single exposure to a sub-cytotoxic dose of UVB resulted in a progressive accumulation of intracellular ROS, which peaked 30 min after UVB irradiation. As shown in Fig. 6A, the presence of RAPA significantly reduced the fluorescence intensity at $30 \mathrm{~min}$, as evidenced by the shift to the left in the curve of the RAPA group detected by the Beckman Coulter Epics Altra flow cytometer (Fig. 6B).

Antioxidants act as a primary defense against free radicals, whereas UVB irradiation significantly decreases the cellular antioxidant status due to excessive ROS generation. However, RAPA treatment induced a 1.2-fold increase in superoxide dismutase 1 (SOD1), a 1.4-fold increase in superoxide dismutase 2 (SOD2), a 2.1-fold increase in catalase (CAT), and a 1.7-fold increase in glutathione peroxidase (GPx) after $48 \mathrm{~h}$ of treatment (Fig. 6C and D).

\section{Discussion}

Our results indicated that RAPA was capable of mitigating some features of UVB-induced senescence in MDFs. UVB-exposed MDFs pretreated with RAPA showed a significant decrease in staining intensity and the percentage of SA- $\beta$-gal-positive cells and rescue of the elongated cell shape. UVB irradiation-mediated CPD formation can lead to apoptotic cell death in dermal cells, with the severity of DNA damage serving as a crucial molecular trigger [32, 33]. Our previous experiments showed that UVB caused S-phase cell cycle arrest to prevent further DNA damage and minimize the likelihood of introducing gene mutations in daughter cells. An early mechanism involved in CPD repair is activation of the DNA damage checkpoint that activates cell cycle delay to allow efficient repair [6]. Nucleotide excision repair (NER) is an important repair system that can remove UV-induced photolesions in placental mammals [34]. However, DNA repair, especially NER in skin cells, may be compromised under oxidative stress conditions induced by UV irradiation [35]. Gueranger et al. found that highly ROS formation could severely limit the efficacy of DNA repair of the proteome [36]. Elodie et al. demonstrated that reduced ROS production could protect DNA repair enzymes against oxidation and repair UV-induced DNA damage in the form of CPDs [37]. The increased ROS production induced by UVB could result in the activation of p53 and p21, which are hallmarks of cellular senescence associated with cell cycle arrest and decreased cell proliferation [38, 39]. While, large number of evidences supported that reduce the formation of ROS could counteract cell-cycle arrest and repression of the expression of UVB induced p53 and p21 [40-42]. Our study showed RAPA treatment could scavenge the deleterious oxidative by increasing the antioxidant enzyme activity and the level of autophagy. Thus, we considered that RAPA could attenuated the cell cycle arrest and reduced the expression of CPDs by reducing the formation of ROS.

Repeated ultraviolet exposure results in skin photoaging, which primarily manifests as coarse wrinkling, a roughened texture, a sallow complexion, and mottled pigmentation [43]. The underlying mechanism may involve alterations in cellular components and degradation of ECM components, including collagen and elastin fibers, in the dermis [44]. Tashiro et al. demonstrated that UVB irradiation increased MMP expression and suppressed type I collagen synthesis [31]. Many studies have shown that exposure to UVB upregulates MMP expression, including MMP-1 (collagenase), MMP-2 (gelatinase A), MMP-3 (stromelysin), and MMP-9 (gelatinase B), which contributes to the degradation of type I collagen $[45,46]$. We observed that RAPA pretreatment increased the synthesis of type I collagen by decreasing MMP-1, $-2,-3$, and -9 expression.

To examine the possible mechanisms underlying the photoprotective effect of RAPA, intracellular ROS level was assessed using the fluorescent probe H2DCF-DA [47]. Di et al. reported that UVB irradiation generated first stage intracellular ROS, such as superoxide radical anions $\left(\mathrm{O}_{2}^{-}\right), \mathrm{H}_{2} \mathrm{O}_{2}$, and hydroxyl radicals $(-\mathrm{OH})$, either directly or through enzyme 


\section{Cellular Physiology Cell Physiol Biochem 2018;46:1849-1860

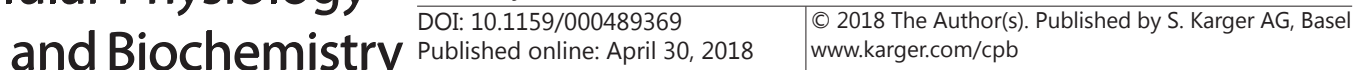 \\ Qin et al.: Rapamycin Protects Skin Fibroblasts from UVB Irradiation}

activation [48]. Based on our results, we propose that the anti-aging mechanism of RAPA occurs by decreasing ROS accumulation and thus increasing the autophagy level. In our study, we found that the autophagy level was significantly reduced in photoaged cells and that RAPA induced a return to a relatively normal autophagy level. RAPA does not cause dysregulated autophagy, which may lead to excessive autophagic cell death and fibroblast dysfunction. By removing the initially damaged mitochondria, aggregated proteins, and ROS, autophagy can provide an effective antioxidant strategy independent of the initiating mechanism. Excessive formation of ROS enhances lipid peroxidation, which results in a decrease in enzymatic and nonenzymatic antioxidants [49]. Our results confirmed that RAPA reduced ROS accumulation by restoring the activity of antioxidants, such as SOD, GPX, and CAT, after UVB irradiation. Several studies have reported that RAPA can increase the level of resistance to oxidation by activating the antioxidant transcription factor Nrf2, which increases the expression of antioxidants [50,51]. RAPA pretreatment also enhanced the levels of endogenous antioxidants in photoaged cells, suggesting that RAPA had the ability to regulate the cellular redox system at the molecular level by activating Nrf2.

However, in this study, we were unable to investigate the autophagy signaling pathway and the possible side effects of RAPA. In future studies, we will explore autophagy and the signaling pathways underlying the observed anti-aging effects.

\section{Conclusion}

In this study, we demonstrated that RAPA ameliorated senescence-like phenotypes, including the flattened morphology, long-term growth arrest, and SA- $\beta$-gal staining. RAPA pretreatment also increased collagen expression and downregulated MMP expression. There may be several explanations for these findings, including an increase in the level of autophagy, improvement of the antioxidant status, and maintenance of the redox balance.

\section{Disclosure Statement}

No conflict of interests exists.

\section{References}

1 Zhou BR, Zhang LC, Permatasari F, Liu J, Xu Y, Luo D: ALA-PDT elicits oxidative damage and apoptosis in UVB-induced premature senescence of human skin fibroblasts. Photodiagn Photodyn Ther 2016;14:47-56. Tobin DJ: Introduction to skin aging. J Tissue Viability 2017;26:37-46.

- 3 Li H, Gao A, Jiang N, Liu Q, Liang B, Li R, Zhang E, Li Z, Zhu H: Protective Effect of Curcumin Against Acute Ultraviolet B Irradiation Induced Photo-damage. Photochem Photobiol 2016;92:

-4 Baek B, Su HL, Kim K, Lim HW, Lim CJ: Ellagic acid plays a protective role against UV-B-induced oxidative stress by up-regulating antioxidant components in human dermal fibroblasts. Korean J Physiol Pharmacol 2016;20:269-277.

-5 Uraiwan P, Gunya S, Natwarath R, Siwanon J: Ultraviolet Radiation-Induced Skin Aging: The Role of DNA Damage and Oxidative Stress in Epidermal Stem Cell Damage Mediated Skin Aging. Stem Cells Int 2016,(2016-4-11) 2016;2016:1-14.

6 Bérubé R, Drigeard MD, Douki T, Lechasseur A, Rochette PJ: Persistence and tolerance of DNA damage induced by chronic UVB irradiation of the human genome. J Invest Dermatol 2017;

7 Britto SM, Shanthakumari D, Agilan B, Radhiga T, Kanimozhi G, Prasad NR: Apigenin prevents ultraviolet-B radiation induced cyclobutane pyrimidine dimers formation in human dermal fibroblasts. Mutat Res 2017;821:28-35.

8 Lan CE, Wang YT, Lu CY, Fang AH, Wu CS: The effect of interaction of heat and UVB on human keratinocyte: Novel insights on UVB-induced carcinogenesis of the skin. J Dermatol Sci 2017; 


\section{Cellular Physiology Cell Physiol Biochem 2018;46:1849-1860 \begin{tabular}{l|l} 
and Biochemistry Published onlıne: April 30, 2018 & $\begin{array}{l}\text { (c) } 2018 \text { The Author(s). Published by S. Karger AG, Basel } \\
\text { www.karger.com/cpb }\end{array}$
\end{tabular}

9 Sun Z, Hwang E, Park SY, Zhang M, Gao W, Lin P, Yi TH: Angelica archangelia Prevented Collagen Degradation by Blocking Production of Matrix Metalloproteinases in UVB-exposed Dermal Fibroblasts. Photochem Photobiol 2016;92:604-610.

10 Karthikeyan R, Kanimozhi G, Prasad NR, Agilan B, Ganesan M, Mohana S, Srithar G: 7-Hydroxycoumarin prevents UVB-induced activation of NF-Î $\mathrm{B}$ and subsequent overexpression of matrix metalloproteinases and inflammatory markers in human dermal fibroblast cells. J Photochem Photobiol B 2016;161:170-176.

-11 Oh Y, Lim HW, Park KH, Huang YH, Yoon JY, Kim K, Lim CJ: Ginsenoside Rc protects against UVB-induced photooxidative damage in epidermal keratinocytes. Mol Med Rep 2017;16:2907.

12 Thiesen LC, Baccarin T, Fischer-Muller AF, Meyre-Silva C, Couto AG, Bresolin TM, Santin JR: Photochemoprotective effects against UVA and UVB irradiation and photosafety assessment of Litchi chinensis leaves extract. J Photochem Photobiol B 2017;167:200.

13 Choi SI, Lee JH, Kim JM, Jung TD, Cho BY, Choi SH, Lee DW, Kim J, Kim JY, Lee OH: Ulmus macrocarpaHance Extracts Attenuated H2O2and UVB-Induced Skin Photo-Aging by Activating Antioxidant Enzymes and Inhibiting MAPK Pathways. Int J Mol Sci 2017;18:1200.

14 Cunningham JT, Rodgers JT, Arlow DH, Vazquez F, Mootha VK, Puigserver P: mTOR controls mitochondrial oxidative function through a YY1-PGC-1 $\alpha$ transcriptional complex. Nature 2007;450:736.

15 Laplante M, Sabatini DM: mTOR signaling in growth control and disease. Cell 2012;149:274-293.

16 Vigneron A, Vousden KH: p53, ROS and senescence in the control of aging. Aging 2010;2:471-474.

17 Samantha G, Victor DU, Jianhua Z: Autophagy as an essential cellular antioxidant pathway in neurodegenerative disease. Redox Biol 2014;2:82-90.

18 Halloran J, Hussong SA, Burbank R, Podlutskaya N, Fischer KE, Sloane LB, Austad SN, Strong R, Richardson A, Hart MJ: Chronic inhibition of mammalian target of rapamycin by rapamycin modulates cognitive and non-cognitive components of behavior throughout lifespan in mice. Neuroscience 2012;223:102-113.

19 Lerner C, Bitto A, Pulliam D, Nacarelli T, Konigsberg M, Van RH, Torres C, Sell C: Reduced mammalian target of rapamycin activity facilitates mitochondrial retrograde signaling and increases life span in normal human fibroblasts. Aging Cell 2013;12:966.

20 Nacarelli T, Azar A, Sell C: Inhibition of mTOR Prevents ROS Production Initiated by Ethidium BromideInduced Mitochondrial DNA Depletion. Front Endocrinol 2014;5:122.

21 Vernon PJ, Tang D: Eat-Me: Autophagy, Phagocytosis, and Reactive Oxygen Species Signaling. Antioxid Redox Signaling 2013;18:677.

-22 Bonawitz ND, Chatenay-Lapointe M, Pan Y, Shadel GS: Reduced TOR signaling extends chronological life span via increased respiration and upregulation of mitochondrial gene expression. Cell Metab 2007;5:265277.

23 Zhang JA, Zhou BR, Xu Y, Chen X, Liu J, Gozali M, Wu D, Yin ZQ, Luo D: MiR-23a-depressed autophagy is a participant in PUVA- and UVB-induced premature senescence. Oncotarget 2016;7:37420-37435.

-24 Fujii S, Hara H, Araya J, Takasaka N, Kojima J, Ito S, Minagawa S, Yumino Y, Ishikawa T, Numata T: Insufficient autophagy promotes bronchial epithelial cell senescence in chronic obstructive pulmonary disease. Oncoimmunology 2012;1:630-641.

25 Sasaki M, Miyakoshi M, Sato Y, Nakanuma Y: Autophagy mediates the process of cellular senescence characterizing bile duct damages in primary biliary cirrhosis. Lab Invest 2010;90:835.

26 Liu W, Otkur W, Zhang Y, Li Q, Ye Y, Zang L, He H, Hayashi T, Tashiro S, Onodera S: Silibinin protects murine fibroblast L929 cells from UVB-induced apoptosis through the simultaneous inhibition of ATM-p53 pathway and autophagy. FEBS J 2013;280:4572-4584.

27 Yang Y, Wang H, Wang S, Xu M, Liu M, Liao M, Frank JA, Adhikari S, Bower KA, Shi X: GSK3 $\beta$ signaling is involved in ultraviolet B-induced activation of autophagy in epidermal cells. Int J Oncol 2012;41:17821788.

-28 Chen LH, Chu PM, Lee YJ, Tu PH, Chi CW, Lee HC, Chiou SH: Targeting Protective Autophagy Exacerbates UV-Triggered Apoptotic Cell Death. Int J Mol Sci 2012;13:1209-1224.

29 Hosokawa M, Ashida Y, Nishikawa T, Takeda T: Accelerated aging of dermal fibroblast-like cells from senescence-accelerated mouse (SAM). 1. Acceleration of population aging in vitro. Mech Ageing Dev 1994;74:65-77.

-30 Zeng JP, Bi B, Chen L, Yang P, Guo Y, Zhou YQ, Liu TY: Repeated exposure of mouse dermal fibroblasts at a sub-cytotoxic dose of UVB leads to premature senescence: a robust model of cellular photoaging. J Dermatol Sci 2014;73:49. 


\section{Cellular Physiology Cell Physiol Biochem 2018;46:1849-1860 \begin{tabular}{l|l} 
and Biochemistry Publisher 10.1159/000489369 & $\begin{array}{l}\text { (c) } 2018 \text { The Author(s). Published by S. Karger AG, Basel } \\
\text { www.karger.com/cpb }\end{array}$
\end{tabular} \\ Published onlIne: April et al: Rapamycin Protects Skin Fibroblasts from UVB Irradiation}

-31 Tashiro K, Shishido M, Fujimoto K, Hirota Y, Yo K, Gomi T, Tanaka Y: Age-related disruption of autophagy in dermal fibroblasts modulates extracellular matrix components. Biochem Biophys Res Commun 2014;443:167-172.

-32 Jeayeng S, Wongkajornsilp A, Slominski AT, Jirawatnotai S, Sampattavanich S, Panich U: Nrf2 in keratinocytes modulates UVB-induced DNA damage and apoptosis in melanocytes through MAPK signaling. Free Radical Biol Med 2017;108:918-928.

-33 Murata Y, Osakabe M: Photo-enzymatic repair of UVB-induced DNA damage in the two-spotted spider mite Tetranychus urticae. Exp Appl Acarol 2017;71:15.

-34 Vrouwe MG, Pines A, Overmeer RM, Hanada K, Mullenders LHF: UV-induced photolesions elicit ATR-kinasedependent signaling in non-cycling cells through nucleotide excision repair-dependent and -independent pathways. J Cell Sci 2011;124:435-446.

-35 Mcadam E, Brem R, Karran P: Oxidative stress-induced protein damage inhibits DNA repair and determines mutation risk and therapeutic efficacy. Mol Cancer Res 2016;14:612.

-36 Gueranger Q, Li F, Peacock M, Larnicol-Fery A, Brem R, Macpherson P, Egly JM, Karran P: Protein oxidation and DNA repair inhibition by 6-thioguanine and UVA radiation. J Invest Dermatol 2014;134:1408-1417.

-37 Metral E, Rachidi W, Damour O, Demarne F, Bechetoille N: Long-term Genoprotection Effect of Sechium edule Fruit Extract Against UVA Irradiation in Keratinocytes. Photochem Photobiol 2017;

-38 Cavinato M, Jansen-Dürr P: Molecular mechanisms of UVB-induced senescence of dermal fibroblasts and its relevance for photoaging of the human skin. Exp Gerontol 2017;94

-39 Ricardo B, Neena P, Suárez-Pérez JA, Angeles J, Avani D, Jovinna CK, Salvador G: Mechanisms of Photoaging and Cutaneous Photocarcinogenesis, and Photoprotective Strategies with Phytochemicals. Antioxidants 2015;4:248-268.

-40 Fan C, Fu X, Zhang Z, Cao M, Sun J, Yang M, Fu X, Zhao S, Shao L, Zhang H: Selenocysteine induces apoptosis in human glioma cells: evidence for TrxR1-targeted inhibition and signaling crosstalk. Sci Rep 2017;7:6465.

41 Chung WK, Choi JY, Park HM, Ji EJ, Kim HD, Park HB, Yu PB, Chung YH: Molecular Insights into SIRT1 Protection Against UVB-Induced Skin Fibroblast Senescence by Suppression of Oxidative Stress and p53 Acetylation. J Gerontol 2015;70:959.

-42 Ruth GL, Gagan D, Harold T, Chapla A, Rajesh A: Silibinin enhances the repair of ultraviolet B-induced DNA damage by activating p53-dependent nucleotide excision repair mechanism in human dermal fibroblasts. Oncotarget 2015;6:39594-39606.

43 Bae JS, Han M, Shin HS, Kim MK, Shin CY, Lee DH, Chung JH: Perilla frutescens leaves extract ameliorates ultraviolet radiation-induced extracellular matrix damage in human dermal fibroblasts and hairless mice skin. J Ethnopharmacol 2016;195:334.

44 Kim EJ, Kim YK, Kim MK, Kim S, Kim JY, Lee DH, Chung JH: UV-induced inhibition of adipokine production in subcutaneous fat aggravates dermal matrix degradation in human skin. Sci Rep 2016;6:25616.

45 Pittayapruek P, Meephansan J, Prapapan 0, Komine M, Ohtsuki M: Role of Matrix Metalloproteinases in Photoaging and Photocarcinogenesis. Int J Mol Sci 2016;17:868.

46 Yamaba H, Haba M, Kunita M, Sakaida T, Tanaka H, Yashiro Y, Nakata S: Morphological change of skin fibroblasts induced by UV Irradiation is involved in photoaging. Exp Dermatol 2016;25 Suppl 3:45.

47 Kong L, Wang S, Wu X, Zuo F, Qin H, Wu J: Paeoniflorin attenuates ultraviolet B-induced apoptosis in human keratinocytes by inhibiting the ROS-p38-p53 pathway. Mol Med Rep 2016;13:3553.

48 Meo SD, Reed TT, Venditti P, Victor VM: Role of ROS and RNS Sources in Physiological and Pathological Conditions. Oxid Med Cell Longevity 2016,(2016-7-12) 2016;2016:1245049.

-49 Petruk G, Illiano A, Del GR, Raiola A, Amoresano A, Rigano MM, Piccoli R, Monti DM: Malvidin and cyanidin derivatives from açai fruit (Euterpe oleracea Mart.) counteract UV-A-induced oxidative stress in immortalized fibroblasts. J Photochem Photobiol B 2017;172:42.

50 Furue M, Uchi H, Mitoma C, Hashimotohachiya A, Chiba T, Ito T, Nakahara T, Tsuji G: Antioxidants for Healthy Skin: The Emerging Role of Aryl Hydrocarbon Receptors and Nuclear Factor-Erythroid 2-Related Factor-2. Nutrients 2017;9:223.

51 Wang R, Sunchu B, Perez VI: Rapamycin and the inhibition of the secretory phenotype. Exp Gerontol 2017;94:89-92. 